\title{
Vulnerability in the elderly
}

\author{
${ }^{{ }_{1}}$ Ana Popescu, ${ }^{1}$ Gabriela Soric, ${ }^{2}$ Victoria Federiuc, ${ }^{2}$ Vitalie Ojovan \\ ${ }^{1}$ Gerontology Laboratory, Department of Internal Medicine, Geriatrics and Occupational Medicine \\ ${ }^{2}$ Department of Philosophy and Bioethics, Nicolae Testemitanu State University of Medicine and Pharmacy \\ Chisinau, the Republic of Moldova
}

\author{
Authors' ORCID iDs, academic degrees and contributions are available at the end of the article \\ *Corresponding author - Ana Popescu, e-mail: ana.popescu@usmf.md \\ Manuscript received April 02, 2021; revised manuscript July 05, 2021; published online September 10, 2021
}

\begin{abstract}
Background: Aging process involves an increased risk for the development of vulnerability, because senescence is a process characterized by a multitude of changes that influence the living conditions and health of the individuals. In geriatrics, the term "vulnerability" implies a multidimensional aspect, among which, multimorbidity, functional incapacity, socio-economic and cognitive problems in the elderly. The main objective of the article is to systematize data from the literature through the analysis of the concept and prevalence of vulnerability, assessed by the score Vulnerable Elders Survey-13 (VES-13) in the elderly. For this purpose, publications from the database GoogleSearch, PubMed, Hinari, etc. were analyzed. The information was systematized, highlighting the main aspects of the contemporary vision of the last 5 years.A series of studies (USA, Brazil, etc.) revealed a high prevalence of vulnerability in the elderly according to the VES- 13 score, it was estimated in respondents aged $>65$ years, between $40-50 \%$ of cases were vulnerable people, with a score $\geq 3 \mathrm{p}$. The vulnerability of the elderly results from different conditions, correlated with each other, especially biological, social and genetic factors. There was a functional decline between 13 and $24 \%$ of cases, especially in the elderly over 75 years, and an association with health problems, mobility and low autonomy in over $50 \%$ of cases, with a poor quality of life and increased risk of institutionalization.

Conclusions: Vulnerability assessment measures are important for identifying older people at high risk of deteriorating health, which is an important target for interdisciplinary intervention.

Key words: elderly, vulnerability, Vulnerable Elders Survey-13 score.
\end{abstract}

Cite this article

Popescu A, Soric G, Federiuc V, Ojovan V. Vulnerability in the elderly. Mold Med J. 2021;64(3):62-67. https://doi.org/10.52418/moldovan-med-j.64-3.21.12.

\section{Introduction}

The increase of the elderly population is considered one of the most significant demographic changes in recent years, which occurred quickly and abruptly and without an adequate monitoring of social and economic processes, so in the context of gerontology we explore the concept of vulnerability, defined as the condition of individuals or a group of people who, for some reason, have a reduced capacity for self-care and who may have difficulty for performing daily needs due to deficits in functionality, cognitive function, financial resources and/or other attributes [1].

Aging poses an increased risk for the development of biological or individual vulnerability of a socio-economic or psycho-social aspect, which interacts with socio-cultural processes and the cumulative effects of poor education, low income and poor lifelong living conditions. These conditions can have a significant negative impact on the elderly, in particular favoring the individual vulnerability strongly associated with bio-physiological components [2]. Although the terms "fragility" and "vulnerability" are widely used in the gerontological literature, they are not the same. In the study of this literature, the term vulnerability is considered as a concept that involves an increased risk of developing functional decline or death over a period of up to 2 years, in relation to the deterioration of biological and physiological factors, and it is considered to be associated with the term of pre-frailty, as a condition that may precede the state of fragility. In order to address adequately the term of vulnerability, it is necessary to analyze this concept and develop/adopt screening tools for the subsequent identification of vulnerable elderly people at different levels of health care. In geriatrics, the term "vulnerability" implies a multidimensional aspect with an increased risk of deteriorating quality of life, subsequent institutionalization and death. Therefore, in the context of gerontology, the concept of vulnerability is explored, which can be defined as the elderly ones with a multidimensional quality of life affected, with an increased risk of loss of autonomy and progression of dependence [1,2].

Despite the growing number of publications analyzing this topic, it can be seen that there is still insufficient knowledge about understanding the vulnerability of the elderly [ 1 , 3]. Identifying vulnerable older people and understanding their causes and consequences is a key task of medical and social policy in developing protocols and measures to improve the quality of life of vulnerable older people. 
The main goal of this proposed article is focused on the analysis of the concept of vulnerability and the existing methods used to detect it in the elderly. The main objectives are to highlight the main aspects of the contemporary vision on vulnerability in the literature, the causes of occurrence, risk factors and the impact on the quality of life of the elderly and society in general.

In order to realize the goal of the study, various specialized books, publications from the GoogleSearch database, Hinari, Pub Med, etc. were studied, including the pages of the official sites of the European Geriatric Society, Italian, French, etc. for the identification of scientific journals dedicated to vulnerability, by using key-words "fragility syndrome", "vulnerability", "vulnerability in the elderly", "VES13 " etc. Also, the bibliography of the selected publications was studied. The information was systematized, highlighting the main aspects of the contemporary vision in works of the last 5 years. According to the search engine, 31 publications were selected (clinical trials and literature review).

\section{Results}

Vulnerability is a state of instability, caused by a reduction in adaptation reserves, with a high risk of dependence, hospitalization, mortality, and an imbalance between somatic, mental and social elements, so the concept of vulnerability is a state of dependence, with an increased risk of addiction and the development of fragility syndrome. The main predisposing factors of vulnerability are: age over $85 y$ rs, loss of autonomy for daily activities and instrumetal daily activities (according to Katz and Lawton scores), inadequate social support (especially in case of loneliness, widowhood, poverty), cognitive function affected by the installation of disorders cognitive impairment (according to mini-Mental Status Examination (MMSE) and/or MoCa tests), decreased nutritional reserves or affected nutritional status (determined by Body Mass Index (BMI) and/or Mini-Nutritional Assessment (MNA) test), physical inactivity, postural instability, depression (according to Hamilton score and/or mini-Geriatric Depression Scale), sensory disturbances, comorbidities, iatrogenic pathology [4-6].

In geriatrics, the term "vulnerability" implies a multidimensional aspect, including age-related changes, multimorbidity, including consequences of enduring diseases, functional disability, socio-economic and cognitive problems in the elderly (fig. 1).

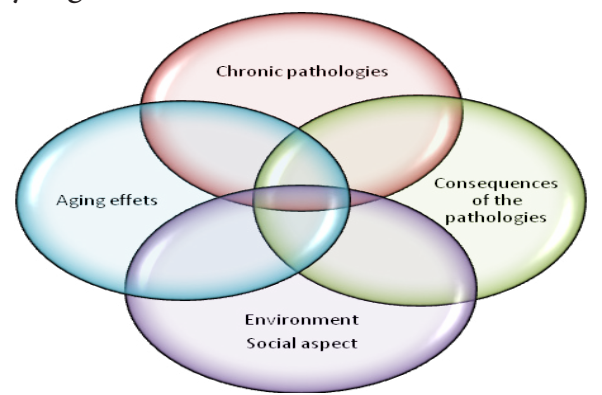

Fig. 1. The multidimensional aspect of vulnerability in the elderly
According to the results of the studies, the identification of people over the age of 65 and who are in a situation of vulnerability, at risk of functional decline and disability is an important and significant step towards building and prioritizing appropriate care for this group of patients $[1,2]$. Through the analysis of the literature, the vulnerability of the elderly results from different conditions, which are correlated with each other, biological, social and genetic factors stand out. Elements such as: biological aging, chronic pathology with deteriorating health, inability of health services, frequent hospitalizations and female gender were identified as precursors to the studied concept. There are 4 major risk factors, which may contribute to the development of vulnerability to the elderly:

$\checkmark$ Functional dependence.

$\checkmark$ Loss of autonomy.

$\checkmark$ Social precariousness.

$\checkmark$ Limited access to care.

The attributes, antecedents and consequences of the concept were identified, presented in figure 2, based on the studied literature.

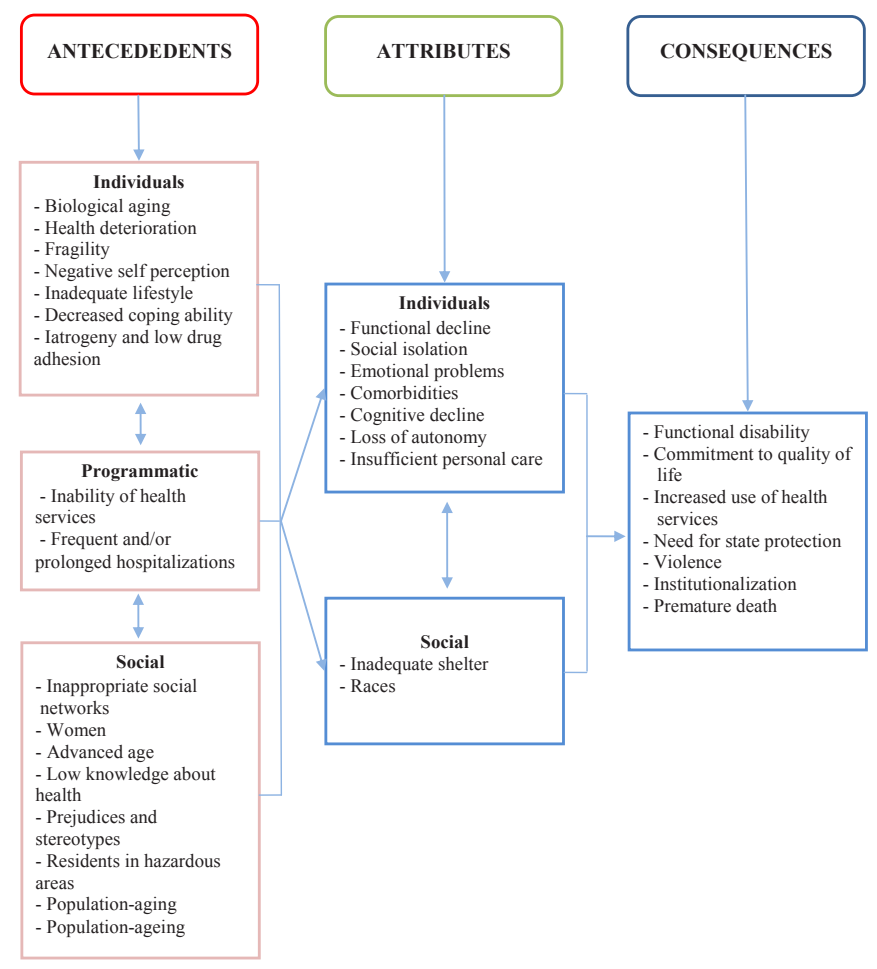

Fig. 2. Background, attributes and consequences of the concept of vulnerability in the elderly, identified from a review of the integrative literature, 2018

There are studies in the literature that describe screening tools for the functional decline and quality of life of vulnerable elderly people $[7,8]$. One of these is the Vulnerable Elders Survey-13 (VES-13), a tool used to predict the onset of functional disability, institutionalization and death of the elderly, included for the first time in the 2014 Health Guide for the Elderly of the Brazilian Ministry of Health, called Protocol for the identification of vulnerable elderly people - VES-13 
[9]. Another tool is Comprehensive Geriatric Assessment that involves functional, cognitive and emotional status assessment scores (ADL, IADL, Tinetti, MMSE, Hamilton). In addition, there are other tests and scores that may be used in some cases, such as: Fried Criteria - evaluating fragility syndrome, SPPB, SARC-F, TUG, TRST, CIRS-G, QLQ-C30, ICOPE.

Vulnerability assessment measures are important for identifying older people at increased risk of deteriorating health, which is an important target for interdisciplinary intervention. Identifying vulnerable people over the age of 60 , at high risk of functional and cognitive decline, is an important and significant step towards building and prioritizing appropriate care for these patients $[1,3]$. There are studies in the literature that describe screening tools for the functional decline and quality of life of the elderly (fig. 3) [4, 5].

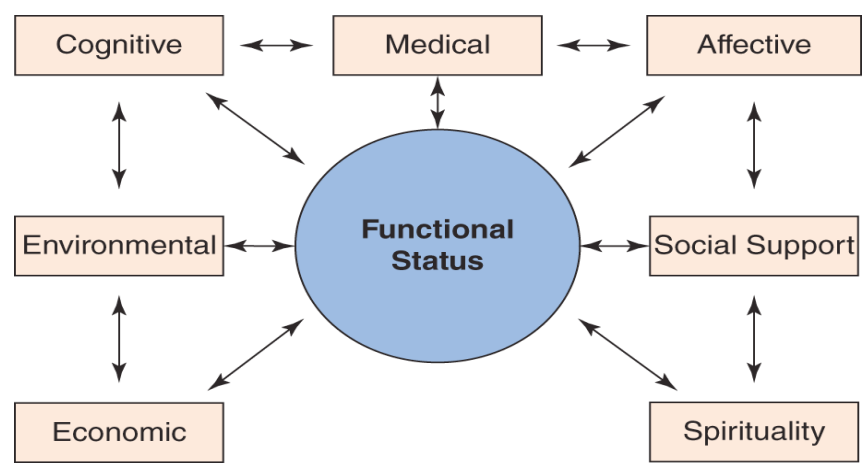

Fig. 3. Multidimensional assessment of vulnerability in the elderly (complex geriatric assessment, ICOPE)

Vulnerable people are those whose autonomy and functionality are impaired, according to this, we can consider that the elderly are those who face chronic diseases, functional decline and loss of social role, being at risk of becoming vulnerable. However, older people do not age uniformly and are vulnerable, for this purpose it is necessary to highlight the risk factors associated with vulnerability in the elderly and the need for intervention to prevent or reduce the degree of vulnerability.

Functional dependence. Functional dependence is defined by the inability to perform daily physical or instrumental activities (ADL, IADL). In Switzerland, $10 \%$ of people over 65 and $20 \%$ of those aged 75 to 94 need help with at least one point in the baseline ADL score (e.g. such as a morning toilet) [3]. The most common pathologies associated with functional decline are: cardiovascular pathology, cerebrovascular disease, stroke, hip fractures, osteoarthritis and cognitive impairment [1]. Functional dependence creates dependence on others, especially on a caregiver.

Loss of autonomy. Autonomy is the ability to decide and function on one's own [5]. Loss of autonomy makes the person vulnerable, depriving him of the power to act alone and imposing decisions made by others. Loss of discernment, in particular, deprives the person of the right to autonomy, especially in the case of dementia and major depression, associated with increased risk of loss of decision-making, depending on the severity of cognitive impairment $[2,6]$. Loss of autonomy in the absence of cognitive deficits can be caused by chronic pathology, which in addition to deep isolation, dependence on others, fear of death and loss of life partner can all affect the patient's autonomy [7].

Social insecurity. Research on the elderly in Switzerland has highlighted two main areas of social precariousness: social isolation and financial problems. Social isolation is associated with poor life quality, impaired physical and cognitive status [8]. In the elderly, physical inactivity is a major risk factor for social isolation and increases the risk by $60 \%$ within two years [9]. In Switzerland, almost 5\% of the population is over 80 years old, this figure is expected to increase dramatically in the next few years due to the aging process. In this age group, almost $42 \%$ of men and $87 \%$ of women experience social isolation, mainly due to widowhood. One consequence is that $24 \%$ of people over the age of 80 years receive medical and social support, at least once a week, and the help of neighbors [10]. Poverty and social isolation, beyond their impact on health, however, remain factors associated with an increased risk for vulnerability, especially when combined with other risk factors.

A number of studies (Brazil, USA, etc.) revealed a high prevalence of vulnerability in the elderly according to the VES-13 score, it was estimated in respondents aged $>65$ years, between $40-50 \%$ of cases were vulnerable people, with a score $\geq 3$ points. The vulnerability of the elderly results from different conditions, correlated with each other, especially biological, social and genetic factors. There was a functional decline between 13 and $24 \%$ of cases, especially in the elderly over 75 years, and an association with health problems, mobility and low autonomy in over $50 \%$ of cases, with a poor quality of life and increased risk of institutionalization.

Starting from studies in the world gerontological literature, in terms of the socio-demographic characteristics of vulnerability, most of the selected scientific papers were pulished on the continent of South America (No 12; 34.3\%), especially in Brazil, where they have conducted 11 studies on the research of this concept, research on vulnerability among the elderly has been started since 2000, predominantly in 2015, 2014 and 2010 (14.0\%), followed by the USA and Europe, highlighting the increased interest of researchers in terms of improving knowledge in this area during last years. In Brazil, two studies were highlighted, which included VES-13, the first in 2014, with 368 respondents, over 65 years, average age 71.4 years, $84 \%$ had $\geq 3$ comorbidities, predominantly sensory disorders $(21.1 \%)$ and hypertension $(19.23 \%)$. When assessing the degree of physical vulnerability, $52.2 \%$ of the elderly were vulnerable, according to VES-13 $\geq 3$ p. Of these, $72.4 \%$ were women, between 70 and 79 years $(41.1 \%)$. There was a decrease in performance of basic and instrumental activities of daily life $(\mathrm{p}<0.001)$. Another quantitative, cross-sectional study was conducted in Distrito Federal, Brazil, on a group of 956 respondents over 60 years, of which $32.4 \%$ had VES-13 scores $\geq 3$ p. clas- 
sified as vulnerable. Some variables showed a positive correlation with the VES-13 score, in the case of hypertension $(p=0.035)$, diabetes $(p=0.027)$, to moderate, in the case of depression $(p<0.001)$, urinary incontinence $(p<0.001)$ and falls ( $\mathrm{p}<0.001)$. It was also observed that a $1 \%$ increase in the income of the elderly led to a reduction of 0.27 points ( $\mathrm{p}<0.001)$ in the VES-13 score, reducing the vulnerability. At the same time, another cross-sectional, descriptive and analytical study, between January 2016 and December 2017, on a number of 1062 respondents, of which $57.3 \%$ were women, the average age of 69 years $( \pm 7.8)$. A total of 427 individuals (40.2\%) were vulnerable and 635 (59.8\%) were not vulnerable according to the VES-13 score. A total of 635 (59.8\%) elderly people were classified as robust, 176 (16.6\%) at risk of fragility and 251 (23.6\%) fragile. According to the results in most studies, women and those over 75 years of age were considered in the most vulnerable category [10]. At the same time, a study conducted in the USA revealed a VES-13> 3points, 32\% of respondents were appreciated as vulnerable, in this group the risk of death is 4.2 times higher and functional decline aprox. 2 years, compared to those who scored $<3$ p. [11]. A pilot study included the elderly with oncological pathology, patients with prostate cancer aged $>70$ years, the vulnerability of this category of elderly was found. Out of 50 participating patients, 50\% were identified as vulnerable according to VES-13 (score $\geq$ 3), $60 \%$ of patients had deficiencies in $\geq 2$ tests in the CGA, with deficiencies in several areas. Patients with VES-13 scores $\geq 3$ p., according to the evaluation of daily activities showed reduced physical performance, comorbidities and cognitive impairment $[11,12]$. In the case of the Caucasian population, the study included 864 respondents (mean age $80.9 \pm 8.2$ years, 615 women) who were hospitalized in the Geriatric Hospital, functional vulnerability presented 91.2\% with a VES-13 score of $\geq 3 \mathrm{p}$. In the case of the Irish population, the assessment of the proportion of vulnerability was assessed as identical to the US sample (32.1\% compared to $32.3 \%$ USA), according to VES-13.

One of the first aspects that is compromised in the aging process is the performance of activities of daily living, mainly because it involves tasks that require greater physical and cognitive integrity, often related to the social participation of the individual, such as shopping, answering the phone and using means of transport. Developed studies have identified routine activities to which older people have reported the greatest difficulties, such as: difficulty of shopping, doing household activities, performing light tasks, such as managing finances and performing the toilet alone $[12,13]$. It should be noted that elderly people with a functional decline are vulnerable to the increased risk of hospitalization, institutionalization and early death, with a 4.2 times higher risk of loss of autonomy and death in the first 2 years after the initial assessment [14].

Studies suggest that older people are vulnerable due to decreased physical and/or mental health. Factors such as deteriorating health, sensory disturbances, cognitive impairments, psychological decline, recurrent episodes of falls and fragility have been strongly linked to the vulnerability of the elderly. Such conditions favor frequent referrals to health services. A significant proportion of vulnerable elderly people need long-term medical care $[15,16]$. Another important aspect highlighted in the literature was gender, as the highest rates of vulnerability and morbidity are attested in women $[12,17,18]$. A Canadian study of older people living in the community showed that life expectancy among women was negatively affected by social problems, such as family and social isolation, economic problems and loneliness [19]. Depression most affected the vulnerability score, followed by urinary incontinence and hearing loss.

Vulnerability involves multiple etiology in the progression of functional decline, the interrelationship between comorbidities such as: heart disease, diabetes, hypertension, Parkinson's disease, and social determinants aggravate this phenomenon [20]. In the case of vulnerable elderly, research shows that social involvement decreases, against the background of a functional and cognitive decline, and a higher frequency of chronic and infectious diseases against which the decrease of interest and empathy towards society appears. There is a need for care adopted for the needs of the elderly, regular assessments of their health, assessment of physical and cognitive status. Performance in instrumental and basic activities of daily living are a widely accepted and recognized parameter for assessing functional capacity, which can be defined as the concrete possibility to manifest the physical and mental abilities necessary for an independent and autonomous life. Multiple comorbidities are a risk factor for functional decline. It was estimated that vulnerability is strongly associated with psychological and physical changes [21, 22].

Biological aging is a continuous process that causes irreversible changes on the body and has a negative impact on the functionality of the individual, sarcopenia is highlighted as a slow, progressive and seemingly inevitable process of loss of strength and muscle mass. It is considered one of the most important physiological changes that occur with the aging process, as it is responsible for reducing functional status and consequently reduced mobility. In the context of this study of the literature, data were identified that vulnerable elderly people have difficulties and/or inability to perform certain mobility-related activities, such as flexion/ extension or kneeling, lifting or carrying a weight of aprx. 5 $\mathrm{kg}$, raising the arm above shoulder level, writing or handling with small objects. Low mobility is the most affected area with repercussions on the health of the elderly, associated with endurance and reduced muscle strength, disability and dependence in performing daily activities [23, 24]. One of the first aspects that is compromised in the aging process is the performance of daily activities, mainly those involving tasks that require greater physical and cognitive integrity, often related to the social participation of the individual, such as shopping, answering the phone and use the means of transport. In vulnerability studies, the elderly reported difficulties in performing various tasks: shopping, managing their own finances and doing household work $[25,26]$. 
A survey conducted in the Netherlands showed that the decline in the performance of instrumental activities varies in the elderly population over 65 , between $13 \%$ and $24 \%$, resulting in a burden for society as a whole and the economy [27]. Regarding the prevalence of dependence for the basic activities of daily living, it was observed that most elderly people had difficulty bathing without help from a caregiver, which was statistically correlated with vulnerability, indicating a significant degree of functional dependence [25, 27].

Losses caused by functional decline can be prevented or minimized if the older adult is encouraged to initiate a specific physical activity program, such as strength training, especially for the lower limbs and under the supervision of suitably qualified professionals. Moreover, the recognition and identification of functional changes can promote early intervention and prevention of disabilities, especially among the elderly [23, 25].

Studies demonstrate the multidimensionality of the studied concept, emphasizing the particularities of vulnerability during aging, there is a need for additional studies in the context of gerontology, because it has significant influence on life quality [1]. Although it is used frequently, the concept is complex and subjective, as there is no agreement in the literature on this phenomenon, thus showing different generic and incipient definitions that often do not take into account the specifics of the elderly, socio-cultural, economic and political interactions with biological processes throughout the life. Therefore, it is important to highlight the need for further studies to understand this concept, allowing its clarification, for its subsequent applicability in practice related to the needs of the elderly.

The degree of vulnerability is subject to a series of combinations of elements present physically, cognitively and socially. Aging is a natural biological process, which over the years, brings many changes, and produces structural and behavioral effects that directly affect the bio-psychosocial aspect and influences the quality of life [16, 28]. Vulnerability assessment measures are important for identifying elderly people at high risk of deteriorating health, which is an important target for interdisciplinary intervention. Vulnerability is determined by gender, age over 75 years and the presence of chronic diseases, these being the priority groups for the elaboration of intervention strategies to improve health condition for elderly people. Elderly patients have unique medical and social problems, especially in the context of long-term care, which depends on available family and social care, as well as the possibilities for diagnosis and the presence of comorbidities, however, the negative effects of senility can be minimized with measures aimed at comprehensive health care. The findings highlighted by the critical analysis of the literature provided relevant theoretical materials, highlighting the particularities of vulnerability in the aging process, with specific regional, gender and age characteristics. Elucidation of characteristics of vulnerability allows theoretically and practically to develop the effective care strategies for the elderly. Public policies aimed at promoting the physical and mental health of the elderly may help reduce the vulnerability for this category of population.

The growing elderly population needs adequate health services by providing comprehensive care. It is very important to recognize vulnerability and to have a multidisciplinary team, in order to promote comprehensive interventions for this category of the elderly $[1,3]$.The aging process involves an increased risk for the development of vulnerability, because senescence is a process characterized by a multitude of changes that influence the health of the elderly, then the quality of life of the individual and society in general.

\section{Conclusions}

Vulnerability assessment measures are important for identifying older people at high risk of deteriorating health, which is an important target for interdisciplinary intervention.

Vulnerability is determined by the gender, age over 75 years and the presence of chronic diseases, these being the priority groups for the development of intervention strategies for health of the elderly.

Elderly patients have unique medical and social problems, especially in the context of long-term care, which depends on the available family and social care, as well as the possibilities for diagnosis and the presence of comorbidities.

\section{References}

1. Carmo ME, Guizardi FL. The concept of vulnerability and its meanings for public policies in health and social welfare. Cad Saúde Pública. 2018;34(3):e00101417. doi: 10.1590/0102-311X00101417.

2. Barbosa KTF, Costa KNFM, Pontes MLF, Batista PSS, Oliveira FMRL, Fernandes MGM. Aging and individual vulnerability: a panorama of older adults attended by the Family Health strategy. Texto Contexto Enferm. 2017;26(2):e2700015. https://doi.org/10.1590/010407072017002700015.

3. Rodrigues NO, Neri AL. Vulnerabilidade social, individual e programática em idosos da comunidade: dados do estudo FIBRA, Campinas, SP, Brasil [Social, individual and programmatic vulnerability among the elderly in the community: data from the FIBRA Study conducted in Campinas, São Paulo, Brazil]. Ciênc Saúde Colet. 2012;17(8):2129-39. Portuguese. https://doi.org/10.1590/S1413-81232012000800023.

4. Arveux I, Faivre G, Lenfant L, et al. Le sujet âgé fragile [The fragile elderly subject]. Rev Gériatr. 2002;27:569-81. French.

5. Rockwood K, Fox RA, Stolee P, Robertson D, Beattie BL. Frailty in elderly people: an evolving concept. CMAJ. 1994;150(4):489-95.

6. Gonthier R. Le concept de fragilité: pourquoi est-il essentiel? [The concept of fragility: why is it essential?]. Rev Gériatr. 2000;25(3):135-8. French.

7. Ayres JRCM, Calazans GJ, Saletti HCJ, França IJ. Risco, vulnerabilidade e práticas de prevenção e promoção da saúde [Risk, vulnerability and health prevention and promotion practices]. In: Akerman M, Campos GWS, Carvalho YM, Drumond MJ, Minayo MCSH, editors. Tratado de Saúde Coletiva [Collective Health Treaty]. 2nd ed. Rio de Janeiro: Editora Fiocruz; 2012. p. 375-418. Portuguese.

8. Talmelli LFS, Gratão ACM, Rodrigues RAP. Modelo híbrido para desenvolvimento de conceito em Enfermagem utilizando revisão integrative e análise de conteúdo [Hybrid model for concept development in Nursing using integrative review and content analysis]. Saúde Transform Soc. 2016;7(1):9-15. Portuguese.

9. Agu FC. Healthy aging reports: a conceptual and ethical analysis of vulnerability and independency. SAGE Open. 2013. https://doi. org/10.1177/2158244013491413. 
10. Amancio TG, Oliveira MLC, Amancio VS. Factors influencing the condition of vulnerability among the elderly. Rev Bras Geriatr Gerontol. 2019;22(2):e180159. https://doi.org/10.1590/198122562019022.180159.

11. Mohile SG, Bylow K, Dale W, Dignam J, Martin K, Petrylak DP, Stadler WM, Rodin M. A pilot study of the vulnerable elders survey-13 compared with the comprehensive geriatric assessment for identifying disability in older patients with prostate cancer who receive androgen ablation. Cancer. 2007 Feb 15;109(4):802-10. doi: 10.1002/cncr.22495.

12. Barbosa KTF, Fernandes MGM, Oliveira FMRL, Tibúrcio ABCB, Alves ABR, Ramos CEB. Vulnerabilidade física entre idosos: diferencias por sexo [Physical vulnerability in elderly: gender differences]. Cultura Cuid. 2015;19(42):90-100. https://doi.org/10.14198/cuid.2015.42.09.

13. Maia FOM., Duarte YAO, Secoli, SR, Santos JLF, Lebrão ML. Crosscultural adaptation of the Vulnerable Elders Survey-13(VES-13): helping in the identification of vulnerable older people. Rev Esc Enferm USP. 2012;46(Spec):116-22. doi: 10.1590/s0080-62342012000700017.

14. Pulignano G, Del Sindaco D, Di Lenarda A, et al. Usefulness of frailty profile for targeting older heart failure patients in disease management programs: a cost-effectiveness, pilot study. J Cardiovasc Med. 2010;11(10):739-47. doi: 10.2459/JCM.0b013e328339d981.

15. Brocklehurst $H$, Laurenson $M$. A concept analysis examining the vulnerability of older people. British J Nurs. 2008;17(21):1354-7. doi: 10.12968/ bjon.2008.17.21.31738.

16. Sarvimäki A, Stenbock-Hult B. The meaning of vulnerability to older persons. Nurs Ethics. 2016;23(4):372-83. doi: 10.1177/0969733014564908.

17. McGee HM, O’Hanlon A, Barker M, et al. Vulnerable older people in the Community: relationship between the Vulnerable Elders Survey and health service use. J Am Geriatr Soc. 2008;56(1):8-15. doi: 10.1111/j.1532-5415.2007.01540.x.

18. Bell SP, Schnelle J, Nwosu SK, et al. Development of a multivariable model to predict vulnerability in older American patients hospitalised with cardiovascular disease. BMJ Open. 2015;5(8):e008122. doi: 10.1136/ bmjopen-2015-008122.

19. Armstrong JJ, Andrew MK, Mitnitski A, et al. Social vulnerability and survival across levels of frailty in the Honolulu-Asia Aging Study. Age Ageing. 2015;44(4):709-12. doi: 10.1093/ageing/afv016.
20. Rubio AE, Lazaro AA, Martinez TT, Magallón B. Enfermedades crónicas y deterioro funcional para las actividades de la vida diaria em población mayor no institucionalizada [Chronic diseases and functional deterioration in activities of daily living in community-dwelling elders]. Rev Española Geriatr Gerontol. 2009;44(5):244-50. Spanish. doi: 10.1016/j. regg.2009.03.011.

21. Wallace LMK, Theou O, Pena F, et al. Social vulnerability as a predictor of mortality and disability: cross-country differences in the survey of health, aging, and retirement in Europe (SHARE). Aging Clin Exp Res. 2015;27(3):365-72. doi: 10.1007/s40520-014-0271-6.

22. Seidel D, Crilly N, Matthews FE, et al. Patterns of functional loss among older people: a prospective analysis. Hum Factors. 2009;51(5):669-80. doi: $10.1177 / 0018720809353597$.

23. Garcia PA., Dias JMD, Dias RC, et al. A study on the relationship between muscle function, functional mobility and level of physical activity in community-dwelling elderly. Rev Bras Fisioter. 2011;15(1):15-22.

24. Van Iersel MB, Munneke M, Esselink RA, et al. Gait velocity and the Timed-Up and-Go Test were sensitive to changes in mobility in frail elderly patients. J Clin Epidemiol. 2008;61(2):186-91. doi: 10.1016/j. jclinepi.2007.04.016.

25. Ursine PGS, Cordeiro HÁ, Moraes CL. Prevalence of housebound elderly people in the urban region of Belo Horizonte (Minas Gerais, Brazil). Ciên Saúde Colet. 2011;16(6):2953-62. doi: 10.1590/s141381232011000600033.

26. Del Duca GF, Silva MC, Hallal PC. Disability relating to basic and instrumental activities of daily living among elderly subjects. Rev Saúde Pública. 2009;43(5):796-805. doi: 10.1590/s0034-89102009010600001.

27. Suijker JJ, Buurman BM, van Rijn M, et al. A simple validated questionnaire predicted functional decline in community-dwelling older persons: prospective cohort studies. J Clin Epidemiol. 2014;67(10):1121-30. doi: 10.1016/j.jclinepi.2014.05.014.

28. Cahir C, Moriarty F, Teljeur C, Fahey T, Bennett K. Potentially inappropriate prescribing and vulnerability and hospitalization in older community-dwelling patients. Ann Pharmacother. 2014;48(12):1546-54. doi: $10.1177 / 1060028014552821$.

\section{Authors' ORCID iDs and academic degrees}

Ana Popescu, MD, Scientific Researcher, Assistant Professor - https://orcid.org/0000-0002-2405-9125

Gabriela Soric, MD, PhD, Coordinating Scientific Researcher - https://orcid.org/0000-0001-5314-2270

Victoria Federiuc, MD, Scientific Researcher, Assistant Professor - https://orcid.org/0000-0002-9029-860X

Vitalie Ojovan, MD, PhD, Associate Professor - https://orcid.org/0000-0003-3510-0477

\section{Authors' contributions}

AP wrote the first manuscript; GS conducted literature review; VF conceptualized the idea; VO revised critically the manuscript and completed the final text. All the authors approved the final version of the manuscript.

\section{Funding}

This study was supported by Nicolae Testemitanu State University of Medicine and Pharmacy. The study was the authors' initiative. The authors are independent and take responsibility for the integrity of the data and accuracy of the data analysis.

\section{Ethics approval and consent to participate}

No approval was required for this study.

\section{Conflict of Interests}

The authors have no conflict of interests to declare. 